\title{
Status of Drug User in Buprenorphine Opioid Substitution Treatment (OST) Center of Kathmandu Valley
}

\author{
Anup Adhikari, Maheshwar Ghimire, Kamana Khatiwada, Kabita Pathak, Rajendra Thapa
}

\begin{abstract}
Status of drug User in Buprenorphine Opioid SubstitutionTreatment (OST) center of Kathmandu Valley was conducted among drug users (both IDUs and DUs) aged 18 years and above who were currently using OST with buprenorphine. This study was directed in four OST centers in Kathmandu Valley with the main objective to assess the status of drug users in buprenorphine opioid substitution therapy.

Descriptive cross sectional study was conducted among 220 respondents using systematic random sampling method.Face to face, interview conducted with respondents using pre-tested, structured interview schedule. Data analyzed by statistical package for social Sciences (25 Version), visualization from $\mathbf{R}$ packages and results were presented in table and figures.

Most of the drug users started using the drugs during their adolescent period. The mean age of fist drug use was 17.1 year. Half of the respondents started using drugs through smoking and $50 \%$ of the respondents first used the drugs under the influence of their peers and friendsand more than $85 \%$ of the respondents have ever injected drugs.
\end{abstract}

Index Terms-Buprenorphine, Drug User, Kathmandu Valley.

\section{INTRODUCTION}

Opioid are psychoactive analgesic drugs prescribed for pain relief and palliative care [1].And the Opioid substitution treatment(OST) is the drug dependent treatment available in many forms; the most commonly used are methadone or

Anup Adhikari, General Secretory, Nepal Family Development Foundation, Lalitpur, Nepal

Maheshwar Ghimire, Treasurer, Nepal Family Development Foundation, Lalitpur, Nepal

Kamana Khatiwada, Nursing Faculty, Tribhuvan University Maharagunj Nursing Campus, Kathmandu, Nepal

Kabita Pathak, Public Engagement officer, Nepal Family Development Foundation(NFDF),Lalitpur,Nepal

Rajendra Thapa, Executive Program Manager, Bridging the Gap; health and rights for the key population project, Youth Vision/ Mainline, Netherland
buprenorphine[2].The multicenter post marketing surveillance study conducted in India reveled that buprenorphine opioid substitution treatment is a safe treatment and cannot make serious adverse effect[3]. And also have less severe neonatal abstinence syndrome than methadone[4], as well as Buprenorphine is an effective intervention for use in the maintenance treatment of heroin dependence[5].

Obtaining attitude towards 417 participantsin USA included 132 individuals entering short-term BT significantly positive attitudes towards buprenorphine than methadone[6].

A systematic review and meta-analysis of prospective observational study from earliest year to 2011, advocates that OST provide as maintenance therapy is associated with a reduction in the in the risk of HIV infected people having HIV[7]. The survey conducted on Malaysia revealed that 102 HIVinfected prisoners $51 \%$ believed that OST is helpful to control the HIV infection[8].

Study of high risky injection practices; 296 male injecting drug user in Kathmandu, $70 \%$ reported that they could share injection equipment with multiple persons[9].

In Nepal, the Buprenorphine treatment ongoing at six sites in Kathmandu, Lalitpur, Jhapa, Rupendehi and Parsa. Contrary to the Methadone Maintenance Therapy, the Buprenorphine treatment provided solely by the NGO sector. The program funded by an international NGOMainline, based in the Netherlands. Two NGOs in Nepal currently implementing the program: Youth Vision in Kathmandu and other sites and Happy Nepal (in collaboration with Youth Vision) in Jhapa[10].

Several study have been conducted in Nepal for opioid substitution therapy, the main objective of the research is to focus the status of buprenorphine opioid substation therapy(OST) clients are drug users receiving OST from four clinics run by Youth Vision in Kathmandu valley. 


\section{MARTIALS AND METHODS}

\section{A. Study area and setting.}

The study conducted in Buprenorphine OSTcenter of Kathmandu Valley. A list of drug users receiving OST from four clinics run by Youth Vision in Kathmandu valley were be collected.

\section{B. Research Design}

The study was descriptive cross-sectional study was conducted to carried out the research.

\section{Samplingtechnique and sample Size}

Systematic random sampling method was used for the data collection and the total sample size was 220 .

\section{Ethical consideration}

The proposed study conducted; initially the consent was taken from the buprenorphine OST centre administrator for the research. Then informed and verbal consent had taken from respondents before asking him/her the questions. Similarly, the respondent should not need to answer all the questions. The respondent allowed quitting if they do not further want to respond.

Questions were not be asked in a way that hurts their dignity. The respondents should assured that the answer they had given remained private, unanimous and confidential.

\section{E. Inclusion and Exclusion criteria}

The participants were the regular visiting client of Youth Vision in Kathmandu valley had included and person below 17 years were excluded.

\section{FINDINGS}

The table I represents the socio-Demographic information of the respondent. Out of 220 drug users receiving OST with buprenorphine from Youth Vision. Among them 138(62.7\%) located from Kathmandu Valley and rest of them 37.3\% were from Lalitpur District. Most of the drug user were male $91.8 \%$ followed by female $8.2 \%$.

The mean age of the drug user was 30 years. Whereas, exactly $37.7 \%$ were belong to age group $25-29$. The educational status of the respondent seems that $97.3 \%$ were literate and only $2.7 \%$ were illiterate. Among them, more than $50 \%$ of drug user had secondary level of education and exactly $46.8 \%$ were married.

Considering about living status of drug user 212(96.4\%) were lived with family and $8(3.6 \%)$ stayed along. Whereas most of them belongs to Brahmin/Chhetri ethnic group and only $2(0.9 \%)$ were from Dalit and foreign nationality, which were categorized in other group.

The main sources of family income was service i.e. $106(48.2 \%)$ followed by labor 11(5\%).considering the employment status $84(48.2 \%)$ were service holder, 52(23.6) had their own business. Among 220 drug less than one third were unemployed.

Table I. Socio-Demographic Information of the Respondent

\begin{tabular}{|c|c|c|}
\hline Background Characteristics(n=220) & Frequency & Percent \\
\hline \multicolumn{3}{|c|}{ Districts } \\
\hline Kathmandu & 138 & 62.7 \\
\hline Lalitpur & 82 & 37.3 \\
\hline \multicolumn{3}{|l|}{ Clinic } \\
\hline Male Clinic & 209 & 95.0 \\
\hline Female Clinc & 11 & 5.0 \\
\hline \multicolumn{3}{|l|}{ Gender } \\
\hline Male & 202 & 91.8 \\
\hline Female & 18 & 8.2 \\
\hline \multicolumn{3}{|l|}{ Age Group } \\
\hline$<20$ & 4 & 1.8 \\
\hline $20-24$ & 29 & 13.2 \\
\hline $25-29$ & 83 & 37.7 \\
\hline $30-34$ & 58 & 26.4 \\
\hline $35-39$ & 30 & 13.6 \\
\hline$\geq 40$ & 16 & 7.3 \\
\hline \multicolumn{3}{|l|}{ Mean $\pm \overline{\mathrm{S}} \mathrm{D}(30.3 \pm 6.6)$} \\
\hline \multicolumn{3}{|l|}{ Educational Status } \\
\hline literate & 214 & 97.3 \\
\hline Illiterate & 6 & 2.7 \\
\hline \multicolumn{3}{|l|}{ Level Of Education } \\
\hline Primary & 13 & 6.1 \\
\hline Secondary & 111 & 51.9 \\
\hline Higher Secondary & 90 & 42.1 \\
\hline \multicolumn{3}{|l|}{ Marital Status } \\
\hline Married & 103 & 46.8 \\
\hline Unmarried & 117 & 53.2 \\
\hline \multicolumn{3}{|l|}{ Living } \\
\hline With Family & 212 & 96.4 \\
\hline Alone & 8 & 3.6 \\
\hline \multicolumn{3}{|l|}{ Caste/Ethnicity } \\
\hline Brahmin/Chhetri & 85 & 38.6 \\
\hline Newar & 59 & 26.8 \\
\hline Janajati & 74 & 33.6 \\
\hline Other & 2 & 0.9 \\
\hline \multicolumn{3}{|l|}{ Source of Family income } \\
\hline Service & 106 & 48.2 \\
\hline Business & 71 & 32.3 \\
\hline Agriculture & 15 & 6.8 \\
\hline Labor & 11 & 5.0 \\
\hline Other & 17 & 7.7 \\
\hline \multicolumn{3}{|l|}{ Employment } \\
\hline Unemployed & 65 & 29.5 \\
\hline Service & 84 & 38.2 \\
\hline Business & 52 & 23.6 \\
\hline Labor & 12 & 5.5 \\
\hline Other & 7 & 3.2 \\
\hline
\end{tabular}

Table II represents the (59\%) entered into drug habit during $15-19$ years of age. among these categories, $23 \%$ male and $22 \%$ female initiated drug use even at a teenier age(10-14). There were very few $(6 \%)$ said that they had begun drug use at the age of 25 years and more. Marijuana (Ganja, Chares, and Bhang) and Brown sugar were the common substance used by male beginners ( $31 \%$ and $31 \%$ respectively) as an entry into drug habit while Marijuana was relatively common substance used by the female beginner (61\%). Brown sugar was less common for female beginners (11\%). Half of male and 44 percent female entered into drug use habit by smoking the substance. One out of three male (32\%) as against one- fifth female (22\%) initiated drug use by 
International Journal of New Technology and Research(IJNTR)

ISSN: 2454-4116, Volume-5, Issue-1, January 2019 Pages 09-14

consuming the drug orally. Moreover, more than double female (28\%) than male (12\%) started using the drug by sniffing. Very few respondents who were currently injecting drugs directly entered into injecting habit from the start (both male and female (5\%).

Table II Distribution of the Respondent with History of Drug Use

\begin{tabular}{cccc}
\multicolumn{2}{c}{ First time of Drug Using } & \multicolumn{2}{c}{ Gender } \\
\hline Age(years) & Male (\%) & Female(\%) & Total (\%) \\
\cline { 2 - 4 }$<10$ & $2(1.0)$ & $0(0.0)$ & $2(0.9)$ \\
$10-14$ & $47(23.3)$ & $4(22.2)$ & $51(23.2)$ \\
$15-19$ & $118(58.4)$ & $11(61.1)$ & $129(58.6)$ \\
$20-24$ & $22(10.9)$ & $2(11.1)$ & $24(10.9)$ \\
$\geq 25$ & $13(6.4)$ & $1(5.6)$ & $14(6.4)$
\end{tabular}

Mean age at first drug use $=\mathbf{1 7 . 1}$

Types

Route

Smoking
Orally

$\begin{array}{ccc}102(50.5) & 8(44.4) & 110(50.0) \\ 64(31.7) & 4(22.2) & 68(30.9) \\ 25(12.4) & 5(27.8) & 30(13.6) \\ 11(5.4) & 1(5.6) & 12(5.5)\end{array}$

Sniffing

Injection

Duration(years)

$\begin{array}{lccc}\leq 5 & 8(4.0) & 4(22.2) & 12(5.5) \\ 6-10 & 57(28.2) & 10(55.6) & 67(30.5) \\ 11-15 & 70(34.7) & 2(11.1) & 72(32.7) \\ \geq 16 & 67(33.2) & 2(11.1) & 69(31.4)\end{array}$

Influenced/Enforced

Friends

Curiosity

122(60.4) 12(66.7)

134(60.9)

Entertainment

$62(30.7)$

2(11.1)

64(29.1)

15(7.4) 2(11.1)

17(7.7)

Family Problems

$2(1.0) \quad 0(0.0)$

$2(0.9)$

Girl/Boy Friends

$\begin{array}{lccc}\text { Ganja } & 65(32.2) & 11(61.1) & 76(34.5) \\ \text { Brown Sugar } & 62(30.7) & 2(11.1) & 64(29.1) \\ \text { Valium/Tablets } & 48(23.8) & 2(11.1) & 50(22.7) \\ \text { Phensidyl } & 6(3.0) & 0(0.0) & 6(2.7) \\ \text { White Sugar } & 5(2.5) & 3(16.7) & 8(3.6) \\ \text { Chares/Heroin } & 5(2.5) & 0(0.0) & 5(2.3) \\ \text { Tidigesic } & 5(2.5) & 0(0.0) & 5(2.3) \\ \text { Norphine } & 4(2.0) & 0(0.0) & 4(1.8) \\ \text { Opioids } & 2(1.0) & 0(0.0) & 2(0.9)\end{array}$

2(11.1) percent started-taking drug out of curiosity. Very few started taking drug for pleasure $(8 \%)$

Fig. 1 Distribution of Respondent with Drug use while using OST

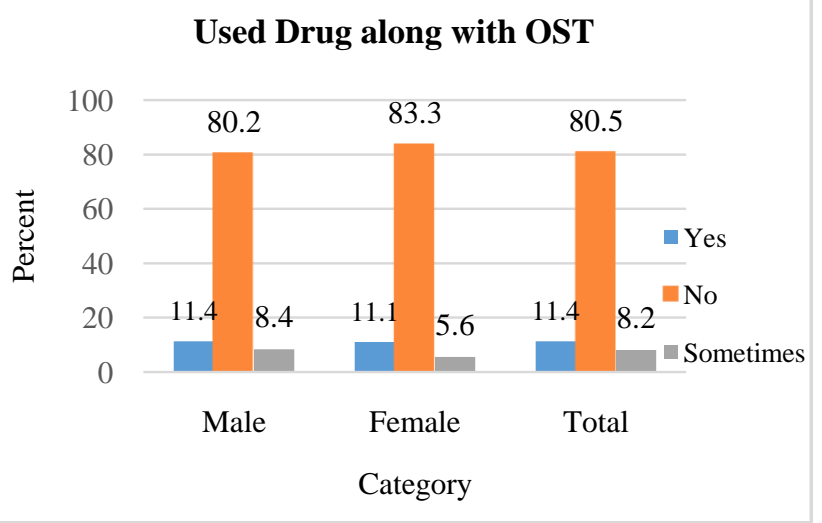

Fig. 1 represents $83 \%$ female and $80 \%$ male did not use drugs during OST. However, 11percent instances of respondents using drugs even after taking OST were reported in the study. Higher proportion of male (8\%) than female $(6 \%)$ have using drug sometime while in OST.

Table III Distribution of the Respondents with the History of Injecting Drug Use

\begin{tabular}{|c|c|c|c|}
\hline Category & Male (\%) & Female (\%) & Total (\%) \\
\hline \multicolumn{4}{|c|}{ Ever Injected Drug } \\
\hline Yes & $172(85.1)$ & $13(72.2)$ & $185(84.1)$ \\
\hline No & $30(14.9)$ & $5(27.8)$ & $35(15.9)$ \\
\hline Total & $202(100.0)$ & $18(100.0)$ & $220(100.0)$ \\
\hline
\end{tabular}

Age at First Injecting

\begin{tabular}{llll}
$10-14$ & $8(4.7)$ & $0(0.0)$ & $8(4.3)$ \\
$15-19$ & $66(38.4)$ & $8(61.5)$ & $74(40.0)$ \\
$20-24$ & $68(39.5)$ & $3(23.1)$ & $71(38.4)$ \\
$\geq 25$ & $30(17.4)$ & $2(15.4)$ & $32(17.3)$ \\
& $172(100.0)$ & $13(100.0)$ & $185(100.0)$ \\
\hline
\end{tabular}

As for the duration of drug used, almost all the respondents had been using drug for more than five years. Of them, over a third male had been using drug for 11-15 years (35\%) and similar number of male are using it for 16 years and above (33\%). On the other hand, Majority of female (56\%) had been using the drug the drug for 6-10 years, while half of the male than female were using the drug for the same period $(28 \%)$. Friends either inspired or enforced to take drug for majority of the respondents (61\%) more than 29
The above table III represents in $84 \%$ of the drug user injected drug in past. Above $44 \%$ of them started to use injecting drugs adolescence and before turning 20 years of age. Among them approximately $60 \%$ female and over $43 \%$ male started injecting drug in 15-29 years. The man age of drug injection was 20.8 years for male and 19.8 years for female. 
Table IV Distribution of the Respondents types of Drug Injected

\begin{tabular}{lcc}
\hline \multicolumn{1}{c}{ Types of drug* } & Frequency & Percent \\
\hline Heroin/Brown sugar & 118 & 63.8 \\
$\begin{array}{l}\text { Phenergan/Avil diazepam or other } \\
\text { drugs }\end{array}$ & 119 & 64.3 \\
Tidigeisc/lupigestic/ & & \\
Buprenorphine/Norphine & 129 & 69.7 \\
Tidigesic/lupigesic Norphine along & & \\
with Phenargan/Avil or Diazepam & 156 & 84.3 \\
by injection & & \\
Proxyvon Spasmoproxyvon (SP) & 35 & 18.9 \\
Avil only & 59 & 31.9 \\
Diazepam only & 68 & 36.8 \\
Pethidine/Fortwin & 18 & 9.7 \\
White sugar & 1 & 0.5 \\
Cocaine & 1 & 0.5 \\
\hline \hline
\end{tabular}

* Multiple Response

The above table shows the multiple types of drug used by the drug user among 704 responses most $(84.3 \%)$ of used the combination of drugs, i.e. Tidigesic/Lupigesic Norphine along with Phenargan/Avil or Diazepam by injection and very small and equal proportion of used White sugar and Cocaine (0.5\%).

Table V Distribution of Respondents Injecting Drug while in OST

\begin{tabular}{lcc}
\hline Category & Frequency & Percent \\
\hline Yes & 26 & 11.8 \\
No & 194 & 88.2 \\
If Yes(n=26) & & \\
Insufficiency of Buprenorphine & 11 & 42.3 \\
Rapture & 10 & 38.5 \\
Forced by friend & 5 & 19.2 \\
If No(n=194) & & \\
Sufficiency by Buprenorphine & 112 & 57.7 \\
Never injected & 47 & 24.2 \\
Clean & 28 & 14.4 \\
Family reason & 4 & 2.1 \\
Not getting & 3 & 1.5 \\
\hline \hline
\end{tabular}

Considering about the respondents injecting drug while in OST. Among the 220 respondent $88.2 \%$ never injected drug while taking OST. Among 57.7\% were satisfied with OST and $24.2 \%$ said that they had never injected the drug.
Fig 2. Distribution of Money spend by Drug User according to sex

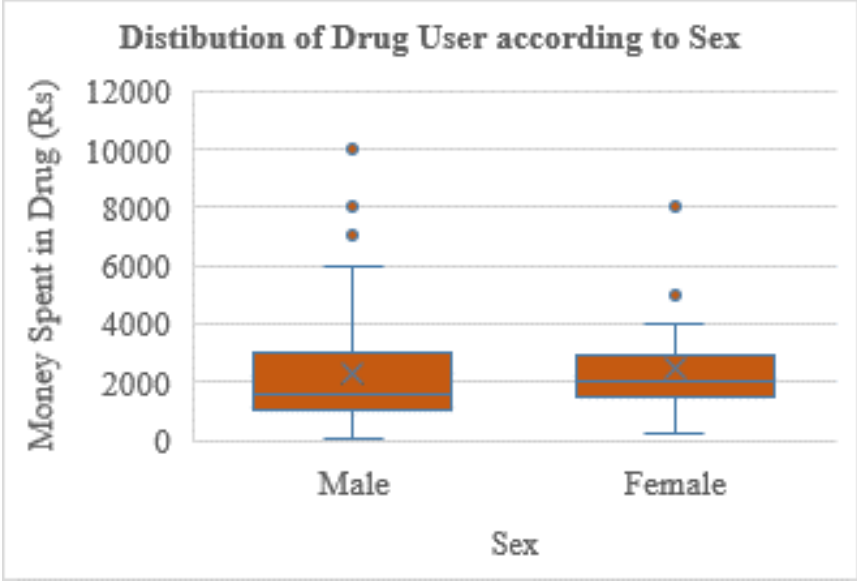

Fig 3. Distribution of Expenditure according to Age

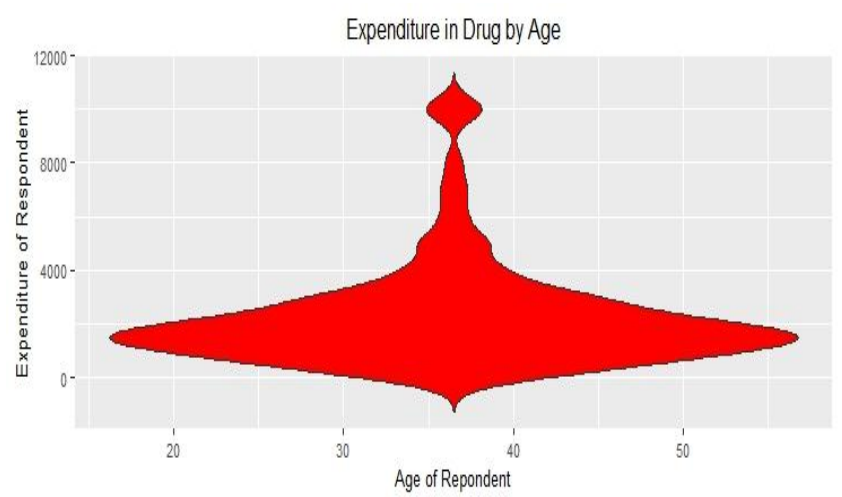

Fig. 2 shows the distribution of money spend by the drug user according to sex. The median expenditure for male and female were Rs. 1150 and Rs. 2000. The minimum and maximum expenses ranges from Rs 88 to Rs 10000 for male and Rs. 200 to Rs. 8000. Which showed the ranges of expenditures were wider in male than female. Furthermore, the fig 3. Shows that distribution of expenditure by age, most of the drug user spend less than Rs. 2000 and most of the drug user lies in the age group of 35-40.

Table VI represents the distribution of the respondent with financial management for drug, majority of the respondents reported that they managed money from family members (57\%), while slightly less than that informed that they spent from their own income (56\%) one fifth managed their expenses with the help of their friends (21\%). Some drug users admitted of stealing/ Selling of utensils of home to meet their drug expenses (9\%). Double of the female (17\%) than male $(8 \%)$ reported of stealing/selling utensils of home to meet their drug expenses. Very few male $(1.5 \%)$ and none of female stated that they used to meet their drug expenses by selling drug (1.5\%). About four-fifth of the drug user spend almost all the money they had earned for the 
drug (79.5\%). Nearly one-fifth spend fifty percent of the money they had earned on drug (18\%)

Table VI Distribution of Respondents with Financial Management for Drug Use

\begin{tabular}{|c|c|c|c|}
\hline & \multicolumn{2}{|c|}{ Sex } & \multirow[t]{2}{*}{ Total (\%) } \\
\hline & Male (\%) & Female (\%) & \\
\hline \multicolumn{4}{|c|}{ Ways of Managing Money For Drug Use From* } \\
\hline Self-Income & $117(57.9)$ & $6(33.3)$ & $123(55.9)$ \\
\hline $\begin{array}{l}\text { Family } \\
\text { Members }\end{array}$ & $118(58.4)$ & $8(44.4)$ & $126(57.3)$ \\
\hline $\begin{array}{l}\text { Get from } \\
\text { Friends }\end{array}$ & $40(19.8)$ & $7(38.9)$ & $47(21.3)$ \\
\hline Stole/Selling & $16(7.9)$ & $3(16.7)$ & $19(8.6)$ \\
\hline $\begin{array}{l}\text { Utensils of } \\
\text { Home }\end{array}$ & & & \\
\hline Selling Drug & $3(1.5)$ & $0(0.0)$ & $3(1.4)$ \\
\hline \multicolumn{4}{|c|}{ Amount of Money Spent from earnings on Drug use } \\
\hline Almost all & $161(79.7)$ & $14(77.8)$ & $175(79.5)$ \\
\hline About half & $35(17.3)$ & $4(22.2)$ & $39(17.7)$ \\
\hline About $25 \%$ & $2(1.0)$ & $0(0.0)$ & $2(0.9)$ \\
\hline Less than $25 \%$ & $1(0.5)$ & $0(0.0)$ & $1(0.5)$ \\
\hline NR & $3(1.5)$ & $0(0.0)$ & $3(1.4)$ \\
\hline
\end{tabular}

* Multiple Response

\section{IV.DISCUSSIONS}

Opioid substitution treatment (OST) is still controversial, despite positive results. The issue of diversion to the illicit drug market is a cornerstone in the criticism typically voiced against the treatment. Little research is available concerning how professionals who work in OST view the issue of diversion[11].

In the present study, we found that some similarities the age at first drug using by the respondent was 17.1 years and above $50 \%$ were employed, which is similar to the nationally published survey report by ministry of home affairs drug control programreported (15-19) years was the age for first drug intake and more than $50 \%$ drug user were employed[12]. However, this findings of our study contradictory to some recently publish paper[13, 14]. Our study has some important strengths first of all we enrolled from different socio economic representatives of different districts. Secondly, the findings of the study have great role to stakeholders and policy makers. However, the study have some limitations such as small sample size and study setting is only in two districts.

\section{CONCLUSION}

This study showed that majority $(91.8 \%)$ male received the OST and the mean age of the respondent was 30 years. Considering about education status most of the respondent were literate (97.3\%). The main sources of family income was service and service is the main employment status.

The mean age of first time of using drug was 17.1 years and initiated from Ganja (Hashish) and main route was smoking enforced by friends. Considering about injecting drug above $80 \%$ of the drug user at teenage.

While taking OST just $11 \%$ started to injecting drug again and above $85 \%$ thinks they were highly satisfied with OST as Buprenorphine and they had ever injected the drugs. Almost eighty percent of respondent spent almost all their income on drug use.

\section{ACKNOWLEDGMENTS}

We thank all study participants and research assistants that contributed to this study. We are also gladful to Youth Vison Nepal. Additionally we want to remember Mr. Sudip Khanal for preparing the manuscripts and statistical analysis.

\section{REFERENCES}

[1] G. M. Franklin, E. A. Rahman, J. A. Turner, W. E. Daniell, and D Fulton-Kehoe, "Opioid use for chronic low back pain: A prospective, population-based study among injured workers in Washington state, 2002-2005," Clin J Pain, vol. 25, pp. 743-51, Nov-Dec 2009.

[2] M. C. Donoghoe, A. Verster, and B. Mathers, "WHO, UNODC, UNAIDS, Technical guide for countries to set targets for universal access to HIV prevention, treatment and care for injecting drug users," 2009.

[3] R. Rajat, P. Hemraj, K. Rajesh, M. Pallab, and M. R., "Post-marketing surveillance of buprenorphine," Pharmacoepidemiology and Drug Safety, vol. 13, pp.615-619, 2004.

[4] J. H. E., H. S. H., B. Andjela, A. A. M., K. Karol, M. P. R., et al., "Buprenorphine treatment of opioid-dependent pregnant women: a comprehensive review," Addiction, vol. 107, pp. 5-27, 2012.

[5] R. P. Mattick, J. Kimber, C. Breen, and M. Davoli, "Buprenorphine maintenance versus placebo or methadone maintenance for opioid dependence," Cochrane Database Syst Rev, vol. 3, p. CD002207, 2004.

[6] S. M. Kelly, B. S. Brown, E. C. Katz, K. E. O'Grady, S. G. Mitchell, S King, et al., "A comparison of attitudes toward opioid agonist treatment among short-term buprenorphine patients," Am J Drug Alcohol Abuse, vol. 38, pp. 233-8, May 2012

[7] G. J. MacArthur, S. Minozzi, N. Martin, P. Vickerman, S. Deren, J. Bruneau, et al., "Opiate substitution treatment and HIV transmission in people who inject drugs: systematic review and meta-analysis," BMJ : British Medical Journal, vol. 345, 2012-10-04 22:32:25 2012.

[8] C. Bachireddy, A. R. Bazazi, R. Kavasery, S. Govindasamy, A Kamarulzaman, and F. L. Altice, "Attitudes toward opioid substitution therapy and pre-incarceration HIV transmission behaviors among HIV-infected prisoners in Malaysia: Implications for secondary prevention," Drug and Alcohol Dependence, vol. 116, pp. 151-157, 2011/07/01/2011

[9] K. C. Poudel, K. Poudel-Tandukar, J. Yasuoka, A. B. Joshi, and M Jimba, "Correlates of sharing injection equipment among male injecting drug users in Kathmandu, Nepal," International Journal of Drug Policy, vol. 21, pp. 507-510, 2010/11/01/2010.

[10] A. Ambekar, A. Pun, and M. S. Kumar, "A Review of Opioid Substitution Therapy (OST) Programme in Nepal."

[11] B. Johnson and T. Richert, "Diversion of Methadone and Buprenorphine from Opioid Substitution Treatment: A Staff Perspective," Journal of Psychoactive Drugs, vol. 46, pp. 427-435, 2014/10/20 2014. 
[12] Government of Nepal Central Bureau of Statististics, "Survey Report on Current Hard Drug Users In Nepal-2069", Ministry of Home Affairs Drug Control Programme, Kathmandu, Nepal 2013.

[13] D. C. Pathak, "Demographic Prevalence of Drug Abuse in youth: Cases from the Surkhet District of Nepal," Journal of Advanced Academic Research, vol. 3, pp. 82-91.

[14] D. J. DeWit, E. M. Adlaf, D. R. Offord, and A. C. Ogborne, "Age at first alcohol use: a risk factor for the development of alcohol disorders," American Journal of Psychiatry, vol. 157, pp. 745-750, 2000 .

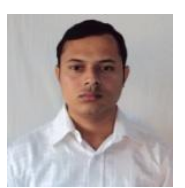

a team leader.

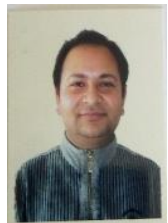

Anup Adhikari is a General secretory of Nepal Family Development Foundation ( NFDF). He had completed master's degree in population studies from Central Department of Population Studies. He had published many research articles in national and international journals. Currently he is working on TyVAC project as

Currently he is working on STRATAA project as a team leader.

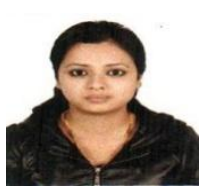

Kamana Khatiwada is a nursing student of Bachelor of Nursing Science at IOM, Maharajung Nursing Campus. She is also working as a staff nurse in Government of Nepal.

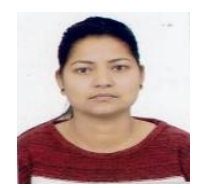

Kabita Pathak is working as a Public Engagement officer in Nepal Family Development Foundation (NFDF). She had completed BPH from Purbanchal University. Currently she is working on TyVAC project.

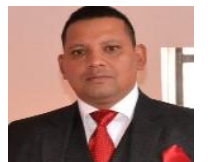

Rajendra Thapa is working as Executive Program Manager, Bridging the Gap; health and rights for the key population project, Youth Vision/ Mainline, Netherland. He had completed Masters in Planning and development, The Global Open University, Nagaland, India in 2010. He had 18 years of experience in HIV prevention, care, support and treatmentespecially among injecting drug users (IDUs), Migrants, Most at risk population (MARPs) and PLHIV. 